\title{
Assessing Customer Attitudes towards Zero Waste Shopping
}

\author{
Storm Watson ${ }^{1 *}$, Elroy Eugene Smith ${ }^{2}$ \\ ${ }^{1,2}$ Department of Business Management, Nelson Mandela University, PO Box 77000, Port Elizabeth, 6031, South Africa
}

\begin{abstract}
Objective - Despite growing concerns for the natural environment and overall public health, waste levels in South Africa remain alarmingly high. A solution suggested to overcome this rising levels of waste is the practice of zero waste shopping. It should be acknowledged that people around the world currently lived through a global pandemic, forcing them into new working and living realities to take responsibility for the state of the planet. This study, however, was conducted before the pandemic started. The purpose of this article was to thus to assess general customer attitudes regarding zero waste shopping.

Methodology/Technique - A quantitative research paradigm was followed. Primary data was collected by means of a survey, using self-administered structured questionnaires. A total of 150 questionnaires were distributed to respondents within the designated population. Responses were captured in a statistical computer programme and descriptive statistics, frequency distributions and reliability testing were conducted.

Findings - The results revealed that most consumers within the designated population are aware of the negative impact of waste generation on the environment and overall public health. The results further revealed that respondents are aware of the concept of zero waste and its basic premises.

Novelty - The study revealed that a significant paradigm shift in consumer attitudes and habits is still required in order for zero waste shopping to be adopted successfully in any developing country.

Type of Paper: Empirical.

JEL Classification: M20; M30

Keywords: Sustainability; Waste; Waste Management; Zero Waste Shopping; Theory Of Planned Behaviour

Reference to this paper should be made as follows: Watson, S; Smith, E.E. (2020). Assessing Customer Attitudes towards Zero Waste Shopping, J. Mgt. Mkt. Review, 5(4) 244 - 250. https://doi.org/10.35609/jmmr.2020.5.4(6)
\end{abstract}

\section{Introduction}

Waste generation is one of the greatest challenges facing society (Hougood Al-Tabbaa, Guthrie \& Watanabe, 2012:2494-2495). In any modern society, waste is regarded as the ultimate symbol of inefficiency and represents a total misallocation of resources (Zaman \& Lehmann, 2013:123). The conceptualisation of zero waste is the most visionary idea for addressing global waste issues (Cole, Osmani, Quddus, Wheatley \& Kay, 2014:65). Zaman and Lehmann (2011:177) state that zero waste involves designing and managing materials, products and processes in such a way as to avoid and eliminate all waste, thus conserving and recovering every resource from waste streams.

\footnotetext{
* Paper Info: Revised: October 18, 2020

Accepted: December 31, 2020

* Corresponding author: Storm Watson

E-mail: storm.watson@mandela.ac.za

Affiliation: Nelson Mandela University, South Africa
} 
In developing countries, waste management is a major challenge due to the constant generation of waste that poses a burden on municipal budgets due to high waste management costs (Guerrero, Maas \& Hogland, 2013:220). Although South Africa has started its zero-waste journey, Godfrey and Oelofse (2017:1) allege that it is in its infancy stage, especially in terms of policy and technology. Dubihlela and Ngxukumeshe (2016:171) is of the opinion that South African consumers have begun to realise the importance of environmental issues and the ensuing health problems associated with these issues. They have thus progressively become more open to solving issues regarding environmental protection and have also become sensitive to the use of environmentally-friendly products, given rise to the debate of zero waste shopping. A study of this nature could assist in recommending to businesses on how they can adapt their product or service offerings to enhance environmental sustainability and assist in educating consumers on waste management practices. The main research question to be addressed in this article is: What are customer attitudes towards zero waste shopping within a designated region in South Africa?

\section{Literature Review}

\subsection{General overview of zero waste}

Oelofse and Godfrey (2008:244) state that waste is any material, liquid, solid or gas that is unvalued, unwanted and thus, discarded. Furthermore, waste can be categorised as solid, liquid, organic, agricultural, recyclable or bio-medical (Duggal, 2017). Zero waste is an ideology that strives to encourage the creation of goods that are designed in such a way that they can be recycled or repurposed (Alfred, 2016:6). As set out by Song, Li and Zeng (2015:199), zero waste entails redesigning a product's entire life cycle to ensure that it can be recycled and avoid landfills. Good (2015) explains that zero waste shopping is thus concerned with the elimination of all unnecessary waste during an individual's shopping experience. According to Guarany (2018), zero waste shopping entails the elimination of plastic in the form of packaging, the purchase of products that are sourced locally and purchasing only what is needed in order to prevent unnecessary waste. Individuals engaging in zero waste practices also seek to purchase products that have been made out of waste and are durable alternatives to typical disposable products (Pujol-Mazzini, 2017). Strategies employed by both businesses and consumers who wish to be more environmentally friendly must have the principal aim of waste prevention (Bautista-Lazo \& Short, 2013:144). The avoidance of waste or the prevention thereof is a better alternative to attempting to eliminate waste that already exists. According to Lehmann (2011:158), waste avoidance must be given the ultimate priority for those wanting to reduce their carbon footprint, followed by recycling, reusing and then only landfilling or incineration. An approach that has been suggested as a means of achieving waste avoidance or prevention, thus addressing the concerns of increased global waste, is the concept of zero waste (Phillips, Tudor, Bird \& Bate, 2011:335). A major key success factor is diligent planning and the utilisation of a range of skills relevant to waste avoidance. Waste must consequently be recovered, gathered, sorted, managed and developed (Zaman 2014, 683). The key to a successful zero waste strategy is a change in behaviour and lifestyles as well as a shift in attitudes to reduce overall consumption (Lehmann 2011:165).

Organisation for Economic Co-operation and Development (2014) further states that although businesses are being recognised for their efforts towards environmental sustainably (redesigning products by ensuring that they are renewable, recyclable, reusable, ozone friendly and bio-degradable), limited research has been done on how consumer attitudes impact the concept of zero waste shopping.

\subsection{Customer attitudes towards zero waste shopping and the theory of planned behaviour}

Customer attitudes can be defined as a combination of an individual's beliefs, feelings and behavioural intentions toward a concept or idea (Akroush \& Al-beDei, 2015:1355). Measuring and analysing human behaviour has forever been a complex dilemma for various academics to conceptualise (Ajzen, 1991:179). There are various factors that affect a customer's attitudes towards the concept of zero waste shopping. To 
further explore the influence of these factors, a theoretical framework for systematically identifying the determinants of zero waste management behaviour is required (Tonglet, Phillips \& Read, 2004:197). The most applicable theoretical framework that can serve as a basis for analysing customer attitudes towards zero waste shopping is the theory of planned behaviour, developed by Ajzen in 1985. The theory hypothesises that consumer behaviour can be accurately predicted by assessing the individual's attitudes towards the behaviour, subjective norms and perceived behavioural control (Ajzen 1991:179). Most importantly, the theory of planned behaviour can be used to thoroughly examine the aspects that influence behavioural choices in relation to zero waste shopping (Tonglet et al., 2004:197).

\subsection{Impact of the COVID-19 pandemic on zero waste shopping}

Robb (2020) acknowledges that people around the world are living through an unprecedented global pandemic forcing many into new working and living realities. The impact of COVID-19 has been immense and revealing major inequalities and the need to protect vulnerable members of society and the environment. In the context of the coronavirus, the concept of zero waste provides a unique lens through which to examine how to survive a global pandemic and to rebuild economies in a way that is both more equal and less destructive to the planet (Munro 2020). Both Kasch (2020) and Martinko (2020) argue that many stores have temporarily banned bulk buying practices and refuse to allow customers to bring their own bags because of COVID-19. Consuming less and being more discerning about what enters one's home make even more sense during a pandemic. The coronavirus has made it harder to engage in everyday acts and behaviours to take personal responsibility for the state of the planet. However, aspects such as refuse, reuse, reduce and recycle still makes sense even during a pandemic situation (Lim \& Olney, 2020). It might just require new approaches and practices toward zero waste. Regardless of how long the coronavirus epidemic lasts, problems of environmental degradation, climate change, and plastic pollution will still be with us long after the pandemic. The pandemic is likely to alter many aspects of public life forever and bulk and zero waste shopping will be no exception.

\section{Research Methodology}

\subsection{Research paradigm and approach}

There are several research paradigms that exist, some are of a qualitative nature, while others are of a quantitative nature (Davies \& Fisher, 2018:21). This study will make use of a quantitative research methodology and therefore uses a positivist research paradigm. This methodology will assess the attitudes and practices of customers in the Nelson Mandela Bay (NMB) area with regards to zero waste shopping. This study made use of a descriptive research approach and analysis to acquire the relevant data to assist in determining the attitudes and practices of consumers towards zero waste shopping.

\subsection{Data collection}

Sources of secondary data can range from annual reports, journal articles, government publications and reputable internet sources (Struwig \& Stead, 2013:82). For this study, secondary research was obtained by accessing various library databases, textbooks, journal articles and the Internet. Primary research entails the collection of data for the specific research problem at hand (Hox \& Boeijie, 2005:593). Primary data was collected by means of a survey using self-administered structured questionnaires. A total of 150 questionnaires were distributed to respondents within the designated population.

\subsection{Questionnaire design}

The items contained in the measuring instrument, namely the questionnaire were sourced from existing measuring instruments and a number of items were self-developed. The questionnaire was administered to respondents required them to evaluate their responses using a five-point Likert type ordinal scale (Section A 
and B), as well as a dichotomous nominal scale (Section C and D). The questionnaire consisted of four sections:

- Section A determined respondents' general perceptions regarding waste management and environmental sustainability.

- $\quad$ Section B investigated consumers' general attitudes towards zero waste shopping.

- $\quad$ Section $\mathrm{C}$ of the questionnaire assessed individuals' practices regarding zero waste.

- Section D focused on the respondents' biographical information.

\subsection{Data analysis}

The primary data collected from the administered questionnaires was captured using Microsoft Excel and analysed using Statistica, which is a statistical and analytical computer programme. Descriptive statistics were used, namely a measure of central tendency (mean), dispersion (standard deviation) and frequency distributions (percentages). Reliability testing was done through calculating Cronbach's alpha values.

\section{Results}

\subsection{Perceptions regarding waste management, environmental sustainability and zero waste shopping}

Table 1 illustrates descriptive statistics and frequency distributions relating to general perceptions regarding waste management, environmental sustainability and zero waste shopping. This table indicates the mean, standard deviation, frequency distributions and Cronbach's alpha values of the various aspects of the measuring instrument. Note that response categories on the five-point Likert scale for the various statements in the questionnaire were categorised as follows: responses from 1 to 2.333 as disagree; 2.333 to 3.667 as neutral; and 3.667 to 5.00 as agree.

Table 1: Statistics relating to general perceptions regarding waste management, environmental sustainability and zero waste shopping

\begin{tabular}{|c|c|c|c|c|c|c|}
\hline \multirow{2}{*}{ Factor } & \multirow{2}{*}{$\begin{array}{l}\text { Cronbach' } \\
\text { s alpha }\end{array}$} & \multirow{2}{*}{ Mean } & \multirow{2}{*}{$\begin{array}{l}\text { Standard } \\
\text { deviation }\end{array}$} & \multicolumn{3}{|c|}{ Responses (\%) } \\
\hline & & & & Disagree & Neutral & Agree \\
\hline $\begin{array}{l}\text { General perceptions regarding waste } \\
\text { management and environmental } \\
\text { sustainability }\end{array}$ & 0.89 & 3.28 & 0.94 & 17 & 22 & 61 \\
\hline $\begin{array}{c}\text { Perceptions regarding zero waste } \\
\text { shopping }\end{array}$ & 0.94 & 3.80 & 0.95 & 31 & 44 & 25 \\
\hline Knowledge of zero waste (KNOW1-5) & 0.83 & 3.50 & 1.08 & 41 & 43 & 16 \\
\hline Food waste (FOOD 1-5) & 0.80 & 3.93 & 0.89 & 28 & 43 & 29 \\
\hline $\begin{array}{l}\text { Attitudes towards zero waste shopping } \\
\text { (ATT1-ATT5) }\end{array}$ & 0.82 & 3.46 & 1.05 & 46 & 35 & 19 \\
\hline Impact of waste (IMPACT1-5) & 0.80 & 3.96 & 0.90 & 23 & 48 & 29 \\
\hline Challenges of zero waste (CHALL1-5) & 0.76 & 4.07 & 0.85 & 19 & 48 & 33 \\
\hline Benefits of zero waste (BEN1-5) & 0.83 & 3.87 & 0.90 & 27 & 50 & 23 \\
\hline
\end{tabular}

In order to access the reliability of the measuring instrument, Cronbach's alpha coefficient was used. The reliability testing results are depicted in Table 1 . Table 1 clearly shows that all the factors used in the measuring instruments appear to be internally reliable, as all Cronbach's alpha values are above 0.70 . 


\subsection{Results regarding practices about zero waste shopping}

Ten statements (PRAC1 to PRAC10) were used to investigate which general practices respondents undertake in their daily lives with regards to zero waste shopping. Table 2 summarises the frequency distributions regarding the various zero waste shopping practices undertaken by respondents.

Table 2: Descriptive statistics relating to respondents' zero waste shopping practices

\begin{tabular}{|c|c|c|c|c|}
\hline & \multirow[b]{2}{*}{ Statement } & \multicolumn{3}{|c|}{ Frequency of responses \% } \\
\hline & & \multirow{2}{*}{$\underset{2}{\mathbb{Z}}$} & \multirow{2}{*}{ 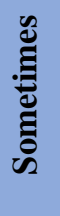 } & \multirow{2}{*}{$\begin{array}{l}\dot{0} \\
\dot{z} \\
\dot{z}\end{array}$} \\
\hline $\begin{array}{c}\text { Statement } \\
\text { code }\end{array}$ & Key words & & & \\
\hline PRAC1 & Reuse shopping bags & 27 & 47 & 25 \\
\hline PRAC2 & Avoid single-use plastics & 14 & 59 & 27 \\
\hline PRAC3 & Reduce packaging waste & 27 & 49 & 23 \\
\hline PRAC4 & Purchase environmentally friendly products & 12 & 62 & 26 \\
\hline PRAC5 & Use own containers as packaging & 8 & 37 & 55 \\
\hline PRAC6 & Avoid harmful cleaning chemicals & 11 & 29 & 59 \\
\hline PRAC7 & Make use of recycling facilities & 16 & 45 & 39 \\
\hline PRAC8 & Reuse items as much as possible & 50 & 41 & 9 \\
\hline PRAC9 & Use alternatives to disposable items & 33 & 49 & 17 \\
\hline PRAC10 & Creative reuse of items to avoid disposal & 40 & 45 & 15 \\
\hline PRAC11 & Pass items on for continued use & 59 & 37 & 4 \\
\hline PRAC12 & Use recycled materials & 13 & 32 & 55 \\
\hline PRAC13 & Search for second-hand items & 23 & 51 & 26 \\
\hline PRAC14 & Reuse food leftovers & 53 & 38 & 9 \\
\hline PRAC15 & Have a compost heap & 11 & 23 & 66 \\
\hline & OVERALL & 27 & 43 & 30 \\
\hline
\end{tabular}

\section{Discussion}

Relating to the respondent's knowledge of zero waste shopping, it was found that although respondents agree with the basic principles of zero waste, such as waste avoidance, reuse, recycling and reduction of waste generation, they often lack knowledge with regard to the efficient implementation thereof. Results relating to food waste indicated that respondents agreed that there is excessive food waste within the economy, and that this has a negative effect on the environment. Respondents had strong feelings about the fact that the cost of wasted edible food could alternatively be used to feed the hungry. Statements used to determine respondents' attitudes towards zero waste also indicated that the majority have a neutral attitude towards the concept of zero waste, yet they have strong feelings about the possible effects on the environment. It was indicated that they are impartial that they already implement the concept of zero waste in their daily lives. The impact of the waste factor showed that respondents are knowledgeable about the impact that waste has on the environment and on their overall personal health. 
Challenges of zero waste proved to be the factor that recorded the highest overall mean score, indicating that the majority of respondents agree that there are various challenges related to the successful implementation of zero waste. The major challenge which affects the successful implementation of zero waste within the NMB area is that individuals, government and schools appear to be uninterested about the efficient management of waste and subsequent implementation of waste management practices, such as zero waste shopping. The results of the benefits of the zero waste factor displayed that respondents are aware of the various benefits that zero waste could pose. It was noted that the most significant benefit of zero waste is that it reduces the hazard to overall public health. It was also noted that respondents agreed that zero waste can have a positive effect on the natural environment, by reducing the extraction of natural resources, thus aiding in the efficient allocation thereof. The majority of respondents strive to continuously reuse items, such as clothing and left-over food to avoid unnecessary waste generation. Half of the respondents also agreed that they always use items as many times as they are able to before discarding them. On the other end of the spectrum, respondents were reluctant to engage in practices that required personal commitment, action and initiative on their part.

\section{Conclusion}

Advocates of the zero-waste lifestyle have emerged and a number of zero waste shops have opened. Zero waste could be seen as an approach which has been suggested as a means of achieving waste avoidance or prevention. However, despite recent developments and trends with regard to the implementation of zero waste, there are still increasing global concerns about levels of waste generation, particularly in developing nations, such as South Africa (Ferronato \& Torretta, 2019:1). Zero waste attempts to eliminate the traditional outlook on waste as something that should be disposed of, and rather encourage people to recognise waste as a valuable resource. South Africa is evidently far behind developed nations with regard to waste management and the shift from simply landfilling waste, to reducing, recycling and reusing waste (Godfrey \& Oelofse, 2017:1).

\section{References}

Ajzen, I. (1991). The theory of planned behavior. Organizational behavior and human decision processes, 50(2), 179211. https://doi.org/10.1016/0749-5978(91)90020-T

Akroush, M.N. \& Al-beDei, M.M. (2015). An integrated model of factors affecting consumer attitudes towards online shopping. Business Process Management Journal, 21(6):1353-1376. DOI: https://doi.org/10.1108/BPMJ-02-2015-0022 Alfred, E. (2016). Zero waste Toronto: A vision for our city. Conference proceedings of Toronto Environmental Alliance. Toronto: 15 February 2016. https://www.torontoenvironment.org/zerowaste

Bautista-Lazo, S., \& Short, T. (2013). Introducing the all-seeing eye of business: a model for understanding the nature, impact and potential uses of waste. Journal of Cleaner Production, 40, 141-150. DOI: https://doi.org.10.1016/j.jclepro.2012.09.011

Cole, C., Osmani, M., Quddus, M., Wheatley, A., \& Kay, K. (2014). Towards a zero-waste strategy for an English local authority. Resources, Conservation and Recycling, 89, 64-75. DOI: https://doi.org/10.1016/j.resconrec.2014.05.005

Davies, C. \& Fisher, M. (2018). Understanding research paradigms. Problems of Education in the 21st Century, 21(3):21-25.https://www.semanticscholar.org/paper/Understanding-research-paradigms-Davies-Fisher/f77306e1a65831 aa2bda87c85e2ff7dc8e3ef484

Dubihlela, J., \& Ngxukumeshe, T. (2016). Eco-friendly retail product attributes, customer attributes and the repurchase intentions of South African consumers. International Business \& Economics Research Journal (IBER), 15(4), 163 174.DOI: https://doi.org/10.19030/iber.v15i4.9754

Duggal, V. (2017). Waste management: Meaning, types/methods, importance, benefits and solutions. https://www.indiacelebrating.com/environmental-issues/waste-management-meaning-types-methods-importance-

benefits-and-solutions

Ferronato, N., \& Torretta, V. (2019). Waste mismanagement in developing countries: A review of global issues. International journal of environmental research and public health, 16(6), 1060. DOI: https://doi.org.10.3390/ijerph16061060 
Godfrey, L., \& Oelofse, S. (2017). Historical review of waste management and recycling in South Africa. Resources, 6(4), 57.DOI: https://doi.org/10.3390/resources6040057

Good, K. (2015). What in the world is a zero waste grocery store and why does the U.S. need one (or many)? https://www.onegreenplanet.org/environment/america-needs-a-zero-waste-grocery

Guarany, J. (2018). The sustainable market: How zero waste shops work. https://believe.earth/en/the-sustainablemarket-how-zero-waste-shops-work

Guerrero, L. A., Maas, G., \& Hogland, W. (2013). Solid waste management challenges for cities in developing countries. Waste management, 33(1), 220-232. DOI: https://doi.org/10.1016/j.wasman.2012.09.008

Hou, D., Al-Tabbaa, A., Guthrie, P., \& Watanabe, K. (2012). Sustainable waste and materials management: national policy and global perspective. DOI: https://doi.org/10.1021/es3004552

Hox, J.J. \& Boeijie, H.R. (2005). Data collection, primary versus secondary. Encyclopaedia of Social Movement, 1(17):593-599. http://joophox.net/publist/ESM_DCOL05.pdf

Kasch, A. (2020). The zero waste movement will survive COVID-19. https://www.envirocenter.org/the-zero-wastemovement-will-survive-covid-19/

Lehmann, S. (2011). Optimizing urban material flows and waste streams in urban development through principles of zero waste and sustainable consumption. Sustainability, 3(1), 155-183. DOI: https://doi.org/10.3390/su3010155

Lim, D. \& Olney, J. (2020). COVID-19 challenges zero waste lifestyle. https:/www./abc7news.com/zero-wastelifestyle-home-bea-johnson/6122391

Martinko, K. (2020). How to keep moving toward zero waste during coronavirus. https:/givingcompass.org/article/how-to-keep-moving-toward-zero-waste-during-coronavirus

Munro, C. (2020). Can the zero waste movement survive coronavirus? It's complicated. Refinery29. https://www.refinery29.com/en-us/zero-waste-living-sustainability-during-coronavirus

Oelofse, S. H. H., \& Godfrey, L. (2008). Defining waste in South Africa: moving beyond the age of'waste'. South African Journal of Science, 104(7-8), 242-246. http://www.scielo.org.za/scielo.php?script=sci_arttext\& pid=S003823532008000400001

Organisation for Economic Co-operation and Development. (2014). Perspectives on global development. Boosting productivity to meet the middle-income challenge. DOI: https://doi.org/10.1787/persp_glob_dev

Phillips, P. S., Tudor, T., Bird, H., \& Bates, M. (2011). A critical review of a key waste strategy initiative in England: Zero waste places projects 2008-2009. Resources, Conservation and Recycling, 55(3), 335-343. DOI: 10.1016/j.resconrec.2010.10.006

Pujol-Mazzini, A. (2017). "Zero waste" stores put consumers on frontline in fight against packaging. https://www.reuters.com/article/us-global-waste-shops/zero-waste-stores-put-consumers-on-frontline-in-fight-againstpackaging-idUSKCN1BF041

Robb, E. (2020). Covid-19 and what it means for our team, for consumers, and for zero-waste globally. https://www.zerowasteeurope.eu/2020/04/covid-19

Song, Q., Li, J., \& Zeng, X. (2015). Minimizing the increasing solid waste through zero waste strategy. Journal of Cleaner Production, 104, 199-210. DOI: https://doi.org/10.1016/j.jclepro.2014.08.027

Struwig, F. W., \& Stead, G. B. (2013). Research: planning, design and reporting.

Tonglet, M., Phillips, P. S., \& Read, A. D. (2004). Using the Theory of Planned Behaviour to investigate the determinants of recycling behaviour: a case study from Brixworth, UK. Resources, conservation and recycling, 41(3), 191-214. DOI: https://doi.org/10.1016/j.resconrec.2003.11.001

Zaman, A. U., \& Lehmann, S. (2011). Urban growth and waste management optimization towards 'zero waste city'. City, Culture and Society, 2(4), 177-187. DOI: https://doi.org/10.1016/j.ccs.2011.11.007

Zaman, A. U., \& Lehmann, S. (2013). The zero-waste index: a performance measurement tool for waste management systems in a 'zero waste city'. Journal of Cleaner Production, 50, 123-132. DOI: https://doi.org/10.1016/j.jclepro.2012.11.041 